\title{
SEX OFFENSES: AN ANTHROPOLOGICAL PERSPECTIVE
}

\author{
CieIIAN S. Ford*
}

\section{InTRODUCTION}

When examining the controls that are imposed upon a type of behavior in our society, it may be useful to have before us a general perspective, a frame of reference obtained from a study of a number of societies quite different from our own. To provide this frame of reference as a background for the assessment of controls imposed upon sex behavior in this country, a cross-cultural study of sex-control was conducted ${ }^{1}$ utilizing primarily the materials contained in the Human Relations Area Files. $^{2}$

To understand our own particular ways of life, our attitudes toward sex, and the formal legislation concerned with sexual matters, it is of paramount importance to have a knowledge of the history of American life-ways. Much has been written on the historical backgrounds of modern European and American sexual behavior. ${ }^{3}$ These studies, together with current sociological and psychological studies of sexual behavior and its social control in this country, provide us with considerable understanding of the situation as it exists in the United States today. Perhaps this is all that is required for an assessment of our moral and legal codes with respect to sex behavior. But it may be that the broader picture provided by the comparative analysis of comparable codes in a number of relatively uncivilized societies may prove to add a useful dimension for evaluation.

The purpose of this article is to provide this broader picture of human sex behavior in societies that have developed their ways of life apart from the great oriental and western cultures. It is by no means a complete picture such as would emerge if the social controls imposed upon sexual behavior in the majority of preliterate societies had been examined. The information used in this analysis relates to a relatively small sample of the world's societies-200 in all. ${ }^{4}$ And the informa-

- Ph.B. I931, Ph.D. 1935, Yale University. Professor of Anthropology, Yale University; President, Human Relations Area Files. Author, Smore From Their Fires (194I), Comparative Study of Human Reproduction (1945), [with Frank A. Beach] Patrerns of Sexual Behavior (I95I).

1 This study is an extension of one aspect of the research that was reported in CleLLan S. Ford \& Frank A. Beach, Patterns in Sexual Behavior (i95i).

${ }^{3}$ This is a research organization composed of 18 member universities that was established in 1949 as a nonprofit corporation with the aim of collecting, organizing, and distributing information of significance to the natural and social sciences and the humanities. The details of this undertaking are elaborated more fully in Human Relations Area Files, A Laboratory for the Study of Man (r959) (obtainable on request from HRAF, Box 2054, Yale Sta., New Haven, Conn.).

${ }^{3}$ Perhaps the most informative single source is Richard Lewisohn, A History of Sexual Customs (Alexander Mayce transl. 1958).

A compendium of the ethnographic files completed or approaching completion, upon which this study has been drawn, is set forth in an appendix hereto. 
tion on them is not as complete as one might wish. But at the same time, these societies do represent a considerable range of behavior and do provide us with some perspective that may be useful when evaluating the status of our own codes with respect to sex behavior.

\section{I}

\section{The Façade of Diversity}

From this comparative analysis, it appears that all societies exert both formal and informal controls over sex behavior. There is, however, an extraordinary diversity in emphasis, in terms of both the kinds of behavior controlled and the circumstances under which controls are imposed. Particularly striking is the fact that people can live lives that are apparently so different from our own-and they have lived and survived that way now for a long time. We find, for example, that there are societies in which the only restriction on sexual activities during childhood and adolescence is the local variation of the incest prohibition. Self-stimulation and both homosexual and heterosexual play on the part of young people are regarded as acceptable and normal activities. By contrast, we find that there are other societies in which all sexual activities on the part of children and adolescents are even more strictly forbidden than they are in puritanical parts of the United States. Knowledge of sexual matters is rigidly excluded from young people's education, and any tendencies they show to experiment in this direction are promptly and rigidly opposed by adults.

We find that in some societies, puberty comes and sexual maturity is reached with very little notice. In other societies, by contrast, there are elaborate rites that mark the transition from childhood to adulthood. For the girl at menarche, these ceremonies may involve a prolonged period of seclusion during which she is instructed in sexual matters and etiquette by older women. She may be tattooed or scarified, her teeth filed or knocked out, her genitals mutilated. Once the instruction and ordeals are over, the girl is greeted as a full-grown woman, a coming-out party is held, and she is considered marriageable.

In some societies, young men are similarly secluded, instructed in matters of etiquette, and mutilated. Such periods of so-called schooling may last for only a few months or may extend as long as several years. The initiation, as in the case of girls, may involve tattooing, scarification, and genital mutilation. The ordeals may be so severe that occasionally youths fail to survive them. The training practices of the Marine Corps seem mild by contrast.

Practices of mating also present considerable diversity. In some societies, this occurs early in life; for others, it is delayed until quite late, so that full reproductive maturity is achieved prior to marriage. The form of marriage, too, varies from society to society. In many, a man is not only permitted, but expected to obtain more than one wife; in a few, the woman is expected to have more than one husband; and in still others, there is even stricter monogamy than we practice and divorce is so rare as to be practically unknown. 
Controls imposed upon extramarital sex affairs also are markedly different from one society to the next. In some, both men and women are severely curtailed in this respect; in others, there are periods of ceremonial license, practices of wifelending, or wife exchange; and in still others, there is relative freedom, particularly for men, and very little censure falls upon the married man who is successful in obtaining the sexual favors of some woman other than his wife.

Prostitution is not a problem in these societies. Nothing comparable to prostitution as it appears in civilized western societies today, or as it existed in the form of temple prostitution among the ancients of the old world, is to be found in the societies of our sample. There are widespread customs of gift-giving as a prelude to or aftermath of sexual favors, oftentimes an exchange of gifts between the sex partners. But these customs can scarcely be thought of in the same light as prostitution, in which sexual favors are traded for a price. They are much more akin to the small favors a suitor in our society may bestow upon the girl of his choice in the form of candy or flowers.

On the other hand, homosexuality, both male and female, is quite commonly reported for many of these societies, and, for some of them, it constitutes a problem, in the sense that they attempt to prevent its occurrence. About one-third of the societies surveyed strongly disapproves of homosexuality, especially in males, and attempts from early childhood to combat any tendencies in this direction. Generally, the sanction imposed is ridicule and derision-although in a few, stronger measures are taken. A very few are so opposed to homosexuality that detected offenders are put to death.

In the remainder of these societies, homosexual behavior, in one form or another, is considered normal and socially acceptable for certain members, or at certain periods along the lifeline. Male homosexuality appears to be more commonly practiced than female homosexuality. Frequently, certain men in a society dress like women, perform female tasks, and play female-like roles in sexual relations with males. In some societies, the man who adopts the role of a women is highly respected and may at the same time occupy the position of a powerful shaman. In other societies, male homosexuality may be expected of all young men in connection with initiation ceremonies.

Along the lifeline, too, there are other controls that may or may not be imposed upon sexual activities. Women, for example, may be forbidden sexual intercourse during menstruation, during all or part of pregnancy, during the postpartum period, and even during the entire period of lactation-two to three years or more. On the other hand, there appear to be societies in which none of these restrictions applies. Women may have intercourse during their menses if they so desire, no restrictions are imposed during pregnancy, and the postpartum period is brief and intercourse resumed soon thereafter. In some societies, there are numerous occasions for abstinence on the part of both men and women. Commonly, before fishing, hunting, or going forth to battle, during certain religious periods, and during mourning, inter- 
course is avoided. By contrast, sexual activities are not only permitted on certain religious and important occasions, but may be mandatory for some people.

The examples presented convey only a partial picture of the diversity in ways of dealing with sexual behavior as obtained through an examination of a number of different societies. But it will serve to demonstrate the point that there is great variation in this respect as one moves from one society to another. This rather extraordinary diversity is somewhat puzzling and requires explanation. We do not yet know what may account for the quite different ways in which people control sexual activities, but a few general matters seem to be relatively clear.

First, there does not appear to be any relationship between the customs that seem the farthest removed from our own and what we might think of as the least advanced or primitive people. Many of our own ways of life are shared by the least civilized. Our monogamous mateship, for example, is to be found among the very primitive Andaman Islanders, whose numbering system stops at three, and the Apinaye of North Central Brazil, peaceful planters with a crude technology. By contrast, our own Mormons, up until some few generations back, practiced polygyny and were certainly not a retarded, primitive people.

Furthermore, it is clear that all is not completely relative and that there are no limits set to the sexual behavior of the members of a society, save traditional and arbitrary codes and attitudes. On the contrary, a comparative study of the social control of sex behavior along the lifeline reveals an extraordinary set of uniformities lying beneath the façade of diversity. Humans are much alike everywhere, and human societies have much in common with each other. People everywhere have a common heritage from organic evolution, the same urges and emotions, the same capabilities for learning and behaving. Through living together, people have faced much the same problems everywhere in their interpersonal relationships. They thus have a comparable heritage from societal evolution, the ways of living and surviving that have been learned, modified, and incorporated into their life-ways.

Nor does the fact of the existence of diversity in the handling of sexual matters from one society to another imply that behavior that may be approved in some other culture, but not our own, is to be recommended for an American. The fact that a number of societies find it congenial for their children to cohabit for several years before marriage is not to say that parents in our society could also take such an attitude lightheartedly. Our society has a structure and culture that is not equally congenial to such behavior, and all sorts of complications would arise were parents suddenly to modify their moral codes in this or other respects.

Conversely, it is clear from the experience of missionaries with indigenous peoples that the artificial imposition of our codes of morality can have disastrous results in terms of the total adjustment of a people and their ways of life. Practices that seem not only meaningless, but downright perverse from our point of view may, in fact, be functional and useful from the point of view of the existence and survival of a particular society. The apparently very cruel and sadistic-like initiation cere- 
monies involving genital mutilations as inflicted upon young boys in certain parts of the world may, in effect, be extremely useful in imposing upon the victims a measure of responsibility and preventing outbreaks of adult aggression that could disrupt their social life.

As indicated above, there is a surprising uniformity characterizing the social control of sex behavior in human societies despite our initial impression of diversity. It may be useful to specify these uniformities in somewhat greater detail. We may begin by examining the controls imposed during childhood and adolescence.

\section{II}

\section{Controls of Chindhood and Adolescence}

Perhaps at the outset, we should state a little more precisely what is meant here by childhood and by adolescence. By childhood is meant the period in a young person's life that extends roughly from the time when he or she begins to walk and talk to the time when signs of puberty appear and are recognized. Puberty, derived from the Latin pubes, meaning hair, is recognizable in the male by the appearance of hair under the armpits and around the genital region. There are other changes that may be pronounced and noticeable, too, such as the deepening of the voice. Usually, the onset of puberty in the male occurs about the age of fourteen. In the female, puberty is dramatically announced by the appearance of the first menses. This generally occurs around the fourteenth year, although menarche may appear either some years earlier or later. Variations in age at onset of puberty are believed to be the consequence of hereditary and dietary factors, but, in fact, very little is known about the variables involved. Climate, apparently, has little or no effect.

For both the boy and the girl, the onset of puberty marks the beginning of sexual maturation. The period between puberty and full reproductive capacity is referred to as adolescence. This is roughly between the ages of fourteen and eighteen for the young man and fourteen and twenty for the young woman. Thus, when adolescents are referred to here, they are, generally speaking, the equivalent of what most Americans may think of as "teen-agers." The fact that puberty and full reproductive maturity do not coincide temporally turns out to be a matter of considerable importance, and this subject will be returned to later in this article.

In any consideration of the controls exerted over the sexual behavior of children and adolescents, it is useful to have in mind some notion of the behavioral heritage that young people have from organic evolution. It seems clear that man's evolutionary heritage has given children both the capacity and a progressively (along the lifeline) stronger tendency for sexual activity of a generalized sort. This type of activity, prior to reproductive maturity, may be referred to as sexual play, since it has no direct reproductive function, and is, thus, not an unnatural thing for children to display. On the contrary, such behavior is to be expected unless social controls intervene to inhibit them. 
Generally speaking, children are brought up within the framework of a family. As is well known, the form of marriage differs from one society to the next. Some are strictly monogamous, others permit a man to take more than one wife, and some (although examples of this are rare) permit a woman to take more than one husband. The formal rulings to which a society adheres in this respect are more divergent, however, than the actual practice. In most of the societies that permit polygyny, relatively few males spend much of their lives with plural wives. In the first place, it appears that in many polygynous societies, only a few men can afford more than one wife, and by the time they can do so, they are well along in life. There are, to be sure, some societies in which there are a number of polygynous households, but these are not as great in number as one would expect from the formal rules concerning plural wives as reported in the literature. The picture that emerges is that for the most part, people live as mated pairs with their children, but that in a number of societies, some men may serve as husband to two or more women and as father to their children.

The degree to which the family is integrated into the social life of the community varies from society to society. From the point of view of the growing child, the type of integration to which he is exposed is probably of considerable importance. Of special importance in terms of controls over sexual activities in childhood and adolescence is the way in which young people are considered to be related to the other members of the community outside of the nuclear family.

\section{A. The Incest Taboo}

The child born in any human society finds himself, then, a part of a family unit. He will be part of larger groupings as well, local and kin, but for the moment, let $u$ see what the family has in store for him. As far as his sex activity is concerned whatever additional controls may be imposed, there will be always one. Apparently in all human societies, for at least the general population, there is a firm prohibition against primary incest-that is, sexual intercourse between son and mother, daughter and father, and brother and sister. There are exceptional instances in some societies, where a small segment of the group is expected by custom to have intercourse with or to marry a primary relative. Among some African societies-the Azande, for example-a chief is expected to have sexual relations with his daughters. And royal families in some societies-such as the Incas of Peru-insisted upon brothersister matings. But instances such as these are uncommon in cross-cultural perspective.

Incestuous liaisons are not, of course, unknown. They apparently do occur in many societies-as, indeed, they do in the United States. But their occurrence is not approved of among any known society by traditional moral standards. If they are detected, such liaisons are generally the subject of public censure. In some societies, severe punishment up to and including the death penalty may be imposed upon the offenders. 
We do not know how and when human societies incorporated into their lifeways the prohibition against primary incest. It does seem clear, however, that it is a part of man's heritage from experience, and not something with which he was endowed at the outset through organic evolution. The twin facts that incestuous relationships can and do occur and that all societies apparently have found it necessary to exert controls over such activities tend to negate any assumption that there is an innate, biological, abhorrence of primary incest. There is a good deal of psychiatric evidence that attraction between son and mother, daughter and father, and brother and sister is quite strong for some individuals in our own society, but has been repressed and fails to find other than fantasy expression. Comparable evidence from dreams and folktales reveals a similar situation in many preliterate societies.

This does not necessarily mean that there is any biologically-given urge for sexual relations with one's parent or child or sibling. It is more likely to be the case that the child comes into the world unbiased in terms of specific targets for sexual advances. Other things being equal, it would seem likely that as his or her sexual interests mature, the growing child would turn to those nearby who have facilitated his other needs and given gratification in other respects. This would seem only natural, unless it were prevented. This, indeed, is what appears to be the case. In other words, it appears that the maturing sex impulse in humans has the objects of its choice defined through experience rather than through any biological inheritance of revulsion or attraction.

As indicated previously, we do not know how or when the prohibtion on primary incest developed. But it is not difficult to imagine how it could have arisen, given the existence of a relatively stable family group. When children are maturin. they are physically at the mercy of their parents. It is not difficult to imagine that competition between a son and father for the same sexual partner would result in the younger one being put in his place. The daughter competing with her mother for the same man would be equally at a disadvantage. The intervention of parents in affairs between their children could easily represent an extension of their dominance over the children's sexual advances toward one or the other spouse. However this may be, the incest prohibition does apparently tend to minimize rivalries within the family, and this function gives the custom considerable survival value. Internal rivalries within the family are generally bad enough as it is without adding sex to the disruptive forces.

The incest prohibition has still another advantage from the point of view of societal survival. It ensures that matings take place outside the nuclear family, thus widening the circle of those who are likely to co-operate with one another in the struggle to survive and band together in face of danger. It also provides for variation in ways of life by bringing together individuals brought up in different families.

The contention that primary incest, if practiced, would be detrimental to human populations from a biological point of view may or may not prove to have merit. The evidence in support of this hypothesis is so scanty that no conclusions can be 
drawn at this time. Certainly, there is no evidence at all that hereditary disadvantages to such close inbreeding gave rise to the incest prohibition, even though the prohibition may have some biological survival value.

The prohibition on incest rarely, if ever, is confined to primary relatives; it extends to other relatives as well. Those thus included vary from one society to the next. In some societies, these are relatively few in number-including, for example, only secondary relatives, such as father's sister, mother's sister, sister's daughter, and brother's daughter. But in a great number of societies, the incest prohibition is extended very broadly-so broadly in many as to preclude intercourse for any individual with half or more of the available members of the opposite sex. This extension of the incest taboo to other than primary relatives has been the object of careful investigation, and it has been related to the kind of social organization and kinship system characterizing each society. ${ }^{5}$

There would seem to be some advantage to the wide extension of the incest prohibition. If it is effective, it limits the number of persons potentially competing for the same sex partner, thus reducing the number of persons involved in direct rivalry with one another. It may mean fiercer competition to be sure, but with relatively few competitors. And the persons with whom the individual competes are more often than not related to one another in such a way as to prevent the rivalry from becoming open hostility and disruptive to the solidarity of the group.

These societal incest taboos, then, provide the basic framework within which the control of a child's sexual activities will be exercised throughout a lifetime. For most societies, we do not know precisely at what age and how this prohibition is inculcated. Generally speaking, it appears that the teaching of the prevailing incest regulation is begun in early childhood, as soon as the young people can talk, as an integral part of the inculcation of the customary and traditional morality.

\section{B. Other Sexual Restraints}

The incest prohibition may not be the only restriction the child faces as he begins to mature. In some societies, as is the case in our own, any evidence of sexual excitement in young boys and girls is something to be avoided and discouraged. In crosscultural perspective, it appears that if restrictions in addition to the incest prohibition are not placed upon growing boys and girls, a certain amount of sex play spontaneously occurs. As they explore their own bodies, children find that they can stimulate their own genitals. As they grow older, they may stimulate the genitals of their playmates. They may simulate coitus in imitation of their elders, especially in societies where there is an opportunity for young people to observe their parents copulating.

For many societies that take a tolerant attitude toward sexual activities in their young people, there is, in addition, free discussion and often detailed instruction in sexual matters. The adults apparently feel that this is an important part of their

" Perhaps the most comprehensive study of this matter is George P. Murdock, Socind. Structurb (1949). 
education, and considerable pains are taken to make sure that the children are properly instructed in all phases of sexual activity and the process of reproduction at an early age. For example, on Ponape, children are given careful instruction in sexual intercourse at the age of four and five.

Among a few societies, the picture is precisely the reverse, very much as it is among ourselves. Here, children are denied any form of sexual expression that is detected by elders. They are warned not to finger their genitals and to avoid any homosexual or heterosexual contact, and they are forbidden to play any games that seem to have sexual connotations. In these societies also, there is conscious attempt on the part of the adults to prevent children from observing sexual behavior and even to refrain from discussing sexual matters in the presence of young people. The Kwoma of New Guinea, perhaps, typify this attitude in clear-cut fashion. Kwoma boys are constantly warned not to finger their genitals. If a woman sees a boy with an erection (they do not wear clothing), she will strike his penis with a stick. Girls also are told not to finger their genitals. Husband and wife in this society are always careful to wait until the children are asleep before indulging in sexual intercourse.

Of course, as in our own society, the formal attitudes toward children indulging in sexual activities do not necessarily mean that such behavior does not occur. Indeed, in American society, as revealed by Kinsey and his associates and others, ${ }^{6}$ considerable sex activity takes place in relative secrecy from adults, both during childhood and adolescence. It may well be that this is the case in other societies where the formal attitude is harsh and discouraging.

The great bulk of the societies surveyed are neither wholly permissive nor rigidly strict with regard to the sex behavior of their children. They seem to take the attitude that such activities on the part of children are to be somewhat discouraged, but not too seriously. The children are supposed to be relatively discreet about their sexual activities and are rarely punished unless the transgression is especially flagrant. Some of these societies are more strict about sexual behavior before signs of puberty are detected.

In the light of the cross-cultural evidence, relatively more pressure is placed upon the growing girl to avoid sexual activities than upon the boy. As in our society, there is in most something of a double standard, with the main responsibility resting upon the girl, and the boy relatively free to get away with as much as he can. This, however, is not always the case. Indeed, there are some societies, as with many African peoples, where the responsibility is directly placed upon the growing boy. They are strictly forbidden to attempt coitus until they have gone through the customary puberty ceremony, and in many, the punishment for transgression is death.

The explanation for the differences in attitudes on the part of adults toward the sexual behavior of children and adolescents is not clear. It might be anticipated

\footnotetext{
- Arfred C. Kinsey, Wardell B. Pomeroy \& Clyde E. Martin, Sexuar Behavior in the Human Male (1948); Alfred C. Kinsey, Wardele B. Pomeroy, Clyde E. Martin \& Paul H. Gebhard, Sexual Behavior in the Human Female (x953).
} 
that the negative and restrictive attitudes reflect concern with premarital pregnancy. In other words, societies that seem especially upset if a girl becomes pregnant before marriage might be the ones that attempt to prevent such a calamity by instilling strict controls over sexual activities beginning at an early age. If marriage, for economic or other reasons, is delayed beyond puberty for any great length of time, it would seem probable that considerable pressures or other means would have to be employed if premarital pregnancies are to be avoided.

The probability of sexual intercourse resulting in conception, however, is not clearcut and completely understood. Sexual maturation in girls and boys is a gradual process that takes several years before they are capable of reproduction. The signs everywhere noted to indicate puberty do not appear to coincide with attainment of reproductive maturity. In the girl, her first menstruation serves everywhere as a dramatic indicator of the onset of puberty, but it may be several years after menarche before the adolescent girl is capable of being successfully impregnated. Evidence from those societies in which adolescent boys and girls regularly indulge in sexual intercourse reveals that only rarely do pregnancies occur for some years after the first recognition of puberty.

Nevertheless, it does seem to be the case that many of the societies that are particularly concerned about premarital pregnancy are the most particular about the sexual behavior of adolescents and children as well. Indeed, for many societies, an unmarried girl's pregnancy is the only real cause for concern. Premarital sexual affairs may be disapproved of in those societies, but permitted to go unnoticed as long as pregnancy does not occur. In a few societies, this is clear-cut and explicit to the point that contraceptive measures are taught the young people and they are told to use them with care.

It is interesting to note in this connection that for a few societies, the attitude is just the reverse. Premarital sexual affairs are permitted and encouraged as a testing ground, as it were, for fertility. Only after a girl has demonstrated that she can conceive is she considered eligible for marriage. This is of particular interest in view of the well-nigh universal acceptance of a wife's childlessness as cause for divorce.

Along somewhat the same line, some societies believe that neither boys nor girls will mature sexually without the benefit of sexual experience. They consider that all phases of sexual maturation-the capability to conceive, to enjoy sexual expression, to achieve proficiency in coitus-depend upon practice beginning early in life; and children are encouraged in this direction. Some also feel that living together as husband and wife should be practiced and experimented with before actual matrimony takes place.

If we now review the general picture, as revealed by this cross-cultural examination of social controls during childhood and adolescence, the following facts emerge: First, control always occurs in the context of the local incest regulations. Second, the 
great majority of societies disapprove of flagrant and public sexual activities by both children and adolescents. Third, children and adolescents everywhere, even in societies where chaperonage is strict and very heavy punishment is threatened for transgression, do engage in some form of sexual activity-self-stimulation, and homosexual and heterosexual activities alike-with an emphasis upon heterosexual coitus during adolescence. Apparently more easily controlled are the specific objects of sexual interest, and the prevailing incest regulations seem to be, for the most part, effective. A fourth general observation is that there does seem to be considerable cross-cultural evidence for the probability that there is quite a long period of adolescence in girls, after menarche, during which they are not fully sexually mature in the sense of being able to conceive and bear a fetus to term.

It is tempting also to hazard the generalization that most societies have found it useful, or at least not detrimental to their welfare, to permit a certain amount of sexual expression on the part of children and adolescents. As long as the prevailing incest regulations are observed and other sexual activities are kept under some control and are not too noticeable, the solidarity of the social group can be maintained without being very much concerned over the sexual activities of young people.

It is too early in our investigations to say with any firm assurance what the varying effects of the different attitudes toward sex in young people may be on the individuals thus maturing. It does seem probable that to insist that all sexual activities be delayed until the wedding night and then to expect the young married couple to perform sexually in a fully satisfactory manner is asking a great deal.

A further matter that requires additional investigation is the possibility that strict sex codes that condemn sexual activity as such may produce difficult conflict situations for young people, since the evidence so overwhelmingly indicates that no matter what parents may do or say, a certain amount of sexual expression is likely to occur. This is an avenue for future research that should prove illuminating.

The relationship of social control over sexual expression and marital adjustment also requires further investigation of a comparative nature before it can be specified with assurance. The studies so far made have been conducted within the framework of our own society. The evidence for Americans tends strongly to suggest that the more inhibited the sexual expression in early life, the more difficult the sexual adjustment in marriage, and that this, among other factors, may be responsible in some instances for an unsuccessful marriage. What we need to know now is whether or not this is also the case in other restrictive societies, and whether the reverse is true of those societies in which a lenient attitude toward early sex activities. is the characteristic pattern.

III

\section{Controls of ADULthood}

We now turn to a consideration of social controls imposed upon sexual activities during adulthood. It is convenient to divide this examination into two parts: control of sex behavior within marriage, and control of extramarital sex behavior. 


\section{A. Marital Sexual Restraints}

Within marriage, there are generally prohibitions against a woman having intercourse during her menstrual period. There are only few societies in cross-cultural perspective that consider the menstruating woman a fit sex partner. Occasionally, intercourse with a woman during menstruation is prescribed under certain circumstances. For example, the Marquesan hubsand is enjoined to have intercourse with his wife if her period is unduly prolonged. In a few societies, a woman may have intercourse during her period if she so desires. But far more generally, the menstrual fluid is considered to be dangerous and unclean. The intimate contact with the menstrual fluid such as that afforded by the sex act is something to be strictly avoided.

In some societies, the prohibition against sexual contact is the only restriction imposed upon the woman during menstruation. In others, she may find additional ones imposed upon her: the avoidance of certain foods, the discontinuation of bathing, and the avoidance of participation in certain forms of social activities such as dancing or feasting. In other societies, the restrictions are even more elaborate and rather completely circumscribe her normal activities. Some force her to remain inactive and in seclusion during her period, either in a special compartment within the dwelling or in a hut set apart, where she is tended by older women.

Apparently, wherever any prohibitions at all are imposed upon the menstruating woman, the prohibition against sexual intercourse is present, thus indicating that it is the intimate contact of the male with the menstrual fluid that is of primary importance. This would suggest then that the additional prohibitions surrounding the woman's activities at this time are predominantly an extension of this fundamental concern. In this connection, it is important to note that the menstruating woman has no muscular control over the flow of blood. Unlike other excretory activities, such as urinating and defecating, the menstrual flow cannot be controlled through voluntary muscular tension. Unless she is provided with some means of preventing the dispersal of the fluid, such as an absorbent plug or pad, she can only keep from contaminating various parts of her environment by avoiding them.

Societies apparently vary in the degree of horror and disgust with which they regard the menstrual fluid. If this feeling is intense, it seems that the woman may be secluded during the period, thus preventing any chance of contamination, whether she is provided with any mechanical means of controlling the flow or not. If the feeling is less intense and one predominantly based on aesthetic values, as it is in our own society, the woman may be secluded or not, depending upon whether there is available for her the equivalent of an absorbent plug or pad. She may, in the latter instance, be permitted complete freedom, with the exception of engaging in sexual intercourse. If there is no horror or disgust of the menstrual fluid, as seems to be the case in a very few societies, no prohibitions apply and even coitus during menstruation may be permitted. 
In most of the societies for which we have the information, it appears that cessation of the menses is regarded as a sign that pregnancy has occurred. In some societies, this is also the signal for a prohibition on sexual intercourse for the woman throughout her term. For other societies, there is no such prohibition during the early part of pregnancy, but one is imposed later on, as the woman increases in size and labor is considered to be only a month or so away. For a number of societies, it is reported that there are no restrictions on sexual intercourse for the pregnant woman. The details are not given, however, and it may be that some adjustment is actually made, in fact, as parturition approaches. In general, it thus appears that for most societies, there is a tendency to avoid intercourse during the later stages of pregnancy, or at least somewhat to modify normal sexual relations; and that for some societies, the prohibition is extended backward in time to cover most, if not all, of recognized pregnancy.

The prohibitions against sexual intercourse during pregnancy are generally supported by the fear that such activity will harm the fetus in one way or another. Some societies feel that it is likely to cause miscarriage or premature birth. Others are convinced that sexual intercourse may bring about deformities or even a stillbirth. This concern over the welfare of the fetus apparently accounts for the fact that the prohibition is levied directly against the pregnant woman's sexual activities. The husband is not similarly restricted, except in so far as the restrictions on extramarital sexual affairs handicap him in monogamous societies. In polygynous societies, he may have access to other wives or to other sex partners. It is interesting to note that only one of the strictly monogamous societies in our sample forbids intercourse with a pregnant woman during the greater part of her term.

After childbirth, the woman in very many societies remains in seclusion for a period of from four to ten days; and for some, the period lasts from two to eight weeks. Even if she is not strictly secluded, the great majority of societies impose sexual abstinence upon the woman for a few weeks after her confinement. Some societies extend the period to several months, and some prohibit the woman to have intercourse during the entire period of lactation, which may last as long as two to three years. In rare instances, the husband has intercourse with his wife immediately after delivery. For these societies, the act is a ceremonial one and required by custom.

There appear to be two basic reasons for the avoidance of sexual intercourse with a woman after childbirth. The first pertains to the few weeks after delivery when the woman is still bleeding. Almost universally, this is a period of sexual abstinence. The second pertains to the probability of a new conception as soon as intercourse is resumed. The societies that insist that the woman abstain from intercourse throughout the period of lactation seem to be convinced that a new pregnancy would rather alter the mother's milk supply, thus forcing her prematurely to wean her child. 
As is the case with the prohibition during a woman's pregnancy, the restriction of sexual intercourse after childbirth and during lactation refers to the mother. Her husband, in those societies where other sex partners are available to him, does not find his sexual activities similarly restricted. Again, it is interesting to note that for the most part, the societies insisting upon a long period of abstinence on the part of the new mother are polygynous. All the societies surveyed here that insist on the prohibition for the entire lactation period are polygynous.

We do not know the reasons for the differences in the controls exercised over marital sex behavior. In some instances, as in the case of intercourse during menstruation, during the first two to three months of pregnancy and just prior to labor, and during a few weeks' postpartum period, there seems to be medical justification for abstinence from sexual activity. No medical reasons justify control of sexual activity during the first year of lactation after the genitalia of the woman have healed, however, save for the possibility of another pregnancy.

In addition to these restrictions, which are tied closely to the reproductive cycle, there are others frequently imposed upon man and wife, as demanded by various circumstances and occasions. For example, in many hunting societies, the hunter, before undertaking an important expedition, is expected to be abstinent. Similarly, in warlike societies, the warrior may be forbidden intercourse prior to battle. Oftentimes, manufacturing processes-like pottery-making and canoe-building-are accompanied by sexual taboos imposed upon the participants. Religious events and ceremonies may also enforce abstinence.

What these social controls during married life mean to the people upon whom they are imposed we do not know. But it would be a most interesting matter to explore. How different must be the sex life of women in societies with no controls imposed upon her-save a mild one during her menses-as compared to others in which the maximum are in force. In societies of the latter sort, it would appear that there is a minimum of opportunity for sexual activity. Forbidden intercourse before marriage, thereafter during her menses until she becomes pregnant, then during all of recognized pregnancy, during the postpartum period, and for a couple of years of nursing, she finds the only time available to her for sexual activities to be the nonmenstruating intervals between successive pregnancies. One must conclude that women live quite different sex lives in these different societies.

With increasing age and the end of child-rearing and menstruation, social controls over the sexual behavior of the woman sharply drop to the point of nonexistence. No record is available from our investigation of a society interfering with marital sexual activities of women in later life, save that imposed when her spouse dies or when, for some reason or another, controls are exercised that have nothing to do with her physiological state. There is very little information available concerning the sexual activities of elderly married people in other societies, but it appears that at least they are little affected by social control. 
B. Extramarital Sexual Restraints

The controls exercised over extramarital sex behavior vary from society to society; but, nevertheless, there is a somewhat surprising over-all uniformity in attitude. In our society, it is generally conceded that all sexual activities should take place within marriage. Both premarital and extramarital liaisons are frowned upon. Adultery is generally a ground for divorce if the fact of the act can be substantiated. There is abundant evidence that extramarital sexual liaisons do occur in our society; but for the most part, they take place in secrecy and are rarely brought to public notice.

A large number of societies seem to take much the same attitude that we do toward extramarital affairs. They are dead set against extramateship sexual liaisons, monogamous and polygynous peoples alike. For most of these societies, the pressures are leveled against the wife, or the wife and her lover. Relatively few seem to concern themselves directly with what the married man does. But he is hedged about with other restrictions, so that in most instances, he will find it difficult to find an unattached and otherwise acceptable sex partner.

The disapproval of sexual liaisons outside of marriage, and even the meting out of divorce and more severe penalties to the offenders, does not mean that violations of the moral code do not occur. In our society, as we earlier indicated, violations occur far more frequently than one would expect from a mere assessment of the articulated standard. But for the societies in our sample, there is little evidence concerning actual frequency of extramateship sexual liaisons in those where there is a general prohibition against such affairs. In some, the penalty for transgression is so severe that it surely must be an extremely inhibiting factor influencing the behavior of would-be lovers, and at the very least accounts for the secrecy with which extramarital sexual affairs are surrounded and the lack of information concerning them available to the investigator.

As in the case of premarital sexual affairs, a focus of concern for many societies is the possibilty of pregnancy resulting from extramarital sexual liaisons. One of the leading reasons given for practicing abortion is that a pregnancy has resulted from an adulterous affair. Contrariwise, there are some societies in which children are accepted, whether or not the pregnancy is known to have resulted from an extramateship sexual affair. In direct contrast to the societies that take an all-out attitude forbidding extramarital sexual liaisons, there are a very few among those investigated in which there is no specific control over sexual activities outside of marriage.

There are some societies that verbally condemn extramateship sexual liaisons, but openly permit them, and no great harm seems to be done even if the affairs are rather public. All of these societies are polygynous, most of them with sororal polygyny, except for one-the Tubatulabal, who are exclusively monogamous. It is difficult to tell from the information, but it would appear that the extramateship sexual liaisons in these polygynous societies take place most frequently between partners who might, under other circumstances, be mated. There seems, for example, to be a high frequency of sexual liaisons between a man and his wife's 
sister, to whom he might well be married under a system of sororal polygyny. In some, there appear also to be frequent sexual liaisons between a woman and her husband's brothers.

Wife-exchange and wife-lending are permitted and expected in some societies. For these, with the possible exception of permitted ceremonial license, to which we will come in a moment, other extramateship sexual liaisons are forbidden. Generally, too, in the case of wife-lending or wife-exchange, sexual access to a man's wife, or an exchange of wives, takes place on only carefully formulated occasions. Hospitality is frequently such an occasion, the guest being offered the host's wife. Usually, too, there is likely to be a return visit, with the former host visiting his guest and sleeping with his wife. In any case, the liaison takes place with public knowledge, and the permission of the husband in each instance is formally given.

A somewhat more general form of permissiveness with respect to extramarital sexual affairs is referred to in the literature as ceremonial license. Quite often, the occasion is religious in nature. It may be, for example, a harvest festival, a period of thanksgiving, or a mortuary feast.

We may now review the findings from this cross-cultural examination of the social control of extramateship sexual liaisons. The first striking fact that emerges is that mateship always characterizes the majority of the population and that extramateship sexual liaisons are always under social control-at the very minimum the control imposed by the primary incest prohibition and its local extension. Where custom permits, there seems to be a strong tendency for extramateships to occur within these limits, and particularly among siblings-in-law. Furthermore, it appears that where custom permits, women avail themselves as eagerly of extramarital sexual liaisons as do the men, thus negating the general principle that by organic heritage, man is more promiscuous than woman. Indeed, if one can judge the strength of a tendency by the severity and frequency of punishment meted out to control sexual activities, it would appear to be the reverse. In the societies that seek to control extramarital sexual liaisons to the point of preventing them altogether, the woman is the prime target of control for the most part.

Of considerable importance is the widespread attempt on the part of societies to control extramarital sexual liaisons. As has been noted, over sixty per cent of t' societies in our sample attempt to exclude them altogether. Most of the remainds. although permitting certain affairs to occur, always seem to have these well formalized and under control. Such customs as wife-lending and wife-exchange and even ceremonial license are rigidly bound into the social code and at all times kept in their place by formal regulation. Apparently, speaking generally, all societies have found it useful to keep extramateship sexual liaisons within bounds as a practical means of keeping intense sexual rivalry at a minimum. Of special interest in this connection is the fact that where extramateship sexual liaisons are permitted, they often take place between siblings-in-law-either real or socially determined. Apparently, the ties that bind brother to brother and sister to sister tend to prevent such: 
rivalry as exists between them to flare into open hostility, thus permitting an exception to the generally disruptive influence of sexual jealousy within the community. Finally, it is worthwhile to note that extramateship sexual liaisons, whether within the socially accepted frame of reference or clandestine and in secret, may well have adaptive value. Women who might otherwise not bear children may by this means become pregnant. Had they been confined during their productive lifetime to a single sex partner, they might have remained childless.

\section{ConcLusion}

The picture of social control over sex behavior sketched above points out clearly that much more research is required before it will be possible to evaluate our own moral and legal codes in this area of activity on the basis of scientific understanding. We know too little about the relationships between social controls of sex behavior and other aspects of human living to be at all dogmatic about the relative desirability of this or that kind of legislation from the point of view of the welfare of either the individual or the society. At the same time, this means that our current moral and legal codes cannot be considered in any way unassailable. On the contrary, they are no more founded upon a scientific understanding of human behavior and social life than are those followed by the most primitive of human societies. Our attitudes toward sexual behavior are based not on science, but upon a traditional code of ethics and morals. They are clearly open to question and deserve careful investigation.

\section{APPENDIX}

\section{WORLD ETHNOGRAPHIC SAMPLE}

\section{Human Relations Area Files}

APRICA

Pygmies \& Khoisan: Hottentot (Nama), Kung Bushmen*

Southern Bantu: Lovedu, Mbundu, Thonga

Central Bantu: Bemba, Yao,* Ndembu*

Northeast Bantu: Chagga, Kikuyu, Nyakyusa

Equatorial Bantu: Fang, Ganda, Mongo, Rundi

Guinea Coast: Ashanti, Mende, Yoruba

Western Sudan: Mossi, Tallensi, Bambara

Nigerian Plateau: Tiv, Nupe, Katab*

Eastern Sudan: Azande, Shilluk*

Upper Nile: Luo, Nuer

CIRCUM-MEDITERRANEAN

Horn \& Ethiopia: Amhara, Somali

Moslem Sudan: Hausa, Wolof

Sahara: Tuareg*

- Files scheduled for completion by July I96r. 
North Africa: Riffians, Siwans*

Southern Europe: Yugoslavians

Overseas Europeans: Americans (Historical Massachusetts)

-Northwest Europe: Irish*

Eastern Europe: Cheremis, Czechs, Estonians, Hungarians, Karelians, Lithuanians, Ukrainians, Russians (Soviet), Zyryans

Caucasia: Circassians, Abkhaz

Near East: Bedouin (Rwala), Jordanians, Syrians, Maritime Arabs, Kuwait

BAST EURASIA

Middle East: Iranians, Afghans

Central Asia: Buryat, Kazak, Uzbek, Khalka

Arctic Asia: Chukchee, Gilyak, Koryak, Ostyak, Samoyed, Yakut, Yukaghir Kamchadal, Tungus

- East Asia: Koreans, Chinese, Lolo, Miao, Yao, Pai-i

Himalayas: Burusho, Dard, Lepcha, Tibetans (Central), West Tibetans

North \& Central India: Bhil, Bihar, Gujerati, Uttar Pradesh

South India: Coorg, Gond (Hill Maria), Kanada, Kerala (Nayar), Telugu (Shamirpet), Toda

Indian Ocean: Andamanese, Tanala

Assam \& Burma: Burmese, Kachin,* Karen,* Khasi

Southeast Asia: Malays, Semang, Thai (Siamese), Vietnamese

INSULAR PACIFIC

Philippines \& Formosa: Atayal, Ifugao, Apayao, Central Bisayans

Western Indonesia: Iban

Eastern Indonesia: Macassarese,* Ambonese,* Balinese*

Australia: Aranda, Tasmanians, Murngin*

New Guinea: Kapauku, Wogeo, Arapesh*

Micronesia: Marshallese,* Ponapeans,* Woleaians (Ifaluk)

Western Melanesia: Buka (Kurtatchi), New Ireland (Lesu),* Trobrianders, Orokaiva*

Eastern Melanesia: Lau Fiijians, Malekulans (Seniang)*

Western Polynesia: Pukapukans, Samoans, Tikopia

Eastern Polynesia: Marquesans, Australs

NORTH AMERICA

Arctic America: Aleut, Kaska, Naskapi, Copper Eskimo

Northwest Coast: Tlingit, Yurok, Nootka*

California: Tubatulabal, Yokuts, ${ }^{*}$ Pomo*

Great Basin \& Plateau: Paiute (Surprise Valley), Sinkaietk, Havasupai*

Plains: Comanche, Crow, Mandan

Prairie: Ojibwa, Omaha, Pawnee*

- Files scheduled for completion by July rg6r. 
Eastern Woodlands: Creek, Iroquois, Delaware*

Southwest: Navaho, Zuni,* Tewa,* Cochiti*

Northwest Mexico: Papago, Tarahumara*

Central Mexico: Aztec, Pame (Chicimeca),* Tarascans*

SOUTH AMERTCA

Central America: Cuna, Miskito

Caribbean: Callinago, Goajiro*

Guiana: Carib (Barama River), Yaruro

Lower Amazon: Mundurucu, Tapirape*

Interior Amazonia: Jivaro, Siriono, Witoto, Tucuna*

Andes: Aymara (Modern), Gayapa, Inca*

Chile \& Patagonia: Araucanians, Tehuelche, Yahgan*

Gran Chaco: Mataco, Guayaki*

Mato Grosso: Nambicuara, Trumai*

Eastern Brazil: Caingang, Timbira (Ramcocamecra), Tupinamba

- Files scheduled for completion by July I96x. 